\title{
Asymmetric Catalysis with MOFs Prepared via Chiral Induction Effect
}

Preparation of homochiral MOF catalysts:

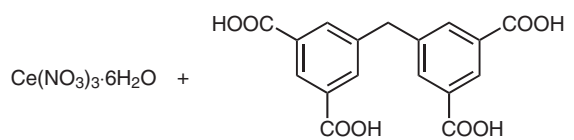<smiles>COC(=O)c1ccc(-c2cc(-c3ccc(C(=O)O)cc3)cc(-c3ccc(C(=O)O)cc3)c2)cc1</smiles>
$\mathrm{H}_{3}$ TBT (1.0 equiv)
$\mathrm{H}_{4}$ MDIP (0.5 equiv)
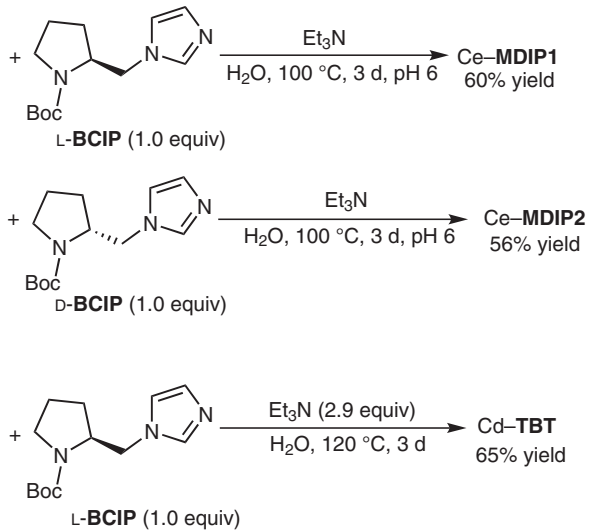

The catalytic cyanosilylation:

Cyanosilylation and aldol reaction using homochiral MOF catalysts:
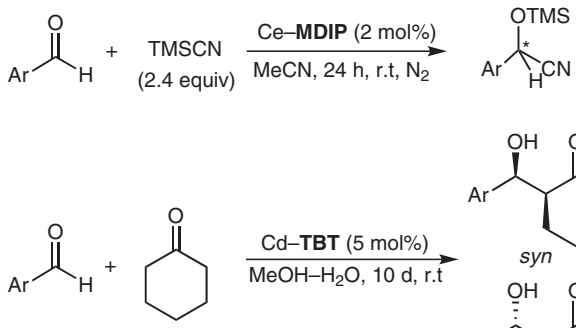

(10 equiv)

\begin{tabular}{cccc}
\hline & & \multicolumn{2}{c}{ ee (\%) } \\
\cline { 3 - 4 } Entry & Ar & Ce-MDIP1 & Ce-MDIP2 \\
\hline 1 & $\mathrm{Ph}$ & 93 & 94 \\
2 & 4-MeO & 91 & 97 \\
3 & 1-Naph & 98 & $>98$ \\
4 & 2-Naph & $>98$ & $>98$ \\
\hline
\end{tabular}

The direct aldol reaction:

\begin{tabular}{cccc} 
& & \multicolumn{2}{c}{ Cd-TBT } \\
\cline { 3 - 4 } Entry & Ar & Yield (\%) & ee (\%) \\
\hline 1 & $2-\mathrm{O}_{2} \mathrm{NC}_{6} \mathrm{H}_{4}$ & 42 & 60 \\
2 & $3-\mathrm{O}_{2} \mathrm{NC}_{6} \mathrm{H}_{4}$ & 77 & 61 \\
3 & $4-\mathrm{O}_{2} \mathrm{NC}_{6} \mathrm{H}_{4}$ & 97 & 58 \\
4 & 1-Naph & 8 & n.d. \\
\hline \multicolumn{3}{r}{ (values represent the major isomer) }
\end{tabular}

Significance: Homochiral metal-organic frameworks (MOFs) were prepared through the chiral induction effect. Thus, the homochiral crystallization of $\mathrm{Ce}\left(\mathrm{NO}_{3}\right) \cdot 6 \mathrm{H}_{2} \mathrm{O}$ and $\mathrm{H}_{4} \mathrm{MDIP}$ was performed with L- or D-BCIP as chiral inducers in water to give Ce-MDIP1 and Ce-MDIP2 (where no BCIP was installed), which exhibited Cotton effects exactly opposite to each other. Ce-MDIPs promoted the cyanosilylation to give the corresponding cyanohydrin derivatives quantitatively with 93 to $>98 \%$ ee.
Comment: Ce-MDIP1 was reused twice without significant loss of catalytic activity. Cd-TBT was also prepared from $\mathrm{Cd}\left(\mathrm{ClO}_{4}\right) \cdot 6 \mathrm{H}_{2} \mathrm{O}$ and $\mathrm{H}_{3}$ TBT under similar conditions. Cd-TBT mediated the direct aldol reaction of aldehydes and cyclohexanone to afford the corresponding $\beta$-hydroxy ketones in $8-97 \%$ yield with $58-61 \%$ ee in ten days. 